\section{(6) OPEN ACCESS}

\title{
Heterogeneity of characteristics, structure, and dynamics of male and hijra sex workers in selected cities of Pakistan
}

\author{
Laura H Thompson, ${ }^{1}$ Momina Salim, ${ }^{2}$ Chaker Riaz Baloch, ${ }^{2}$ Nighat Musa, ${ }^{2}$ \\ Tahira Reza, ${ }^{2}$ Nosheen Dar, ${ }^{2}$ Shahzad Arian, ${ }^{2}$ James F Blanchard, ${ }^{1}$ Faran Emmanuel ${ }^{1,2}$
}

${ }^{1}$ Department of Community Health Sciences, Centre for Global Public Health, University of Manitoba, Winnipeg,

Manitoba, Canada ${ }^{2}$ Canada-Pakistan HIVIAIDS Surveillance Project, Islamabad, Pakistan

\section{Correspondence to} Dr James F Blanchard, Department of Community Health Sciences, Centre for Global Public Health, University of Manitoba, R070-771 McDermot Ave, Winnipeg, MB,

Canada R3E OT6: james_blanchard@umanitoba. ca

Received 30 October 2012 Revised 10 March 2013 Accepted 24 March 2013 Published Online First 20 April 2013

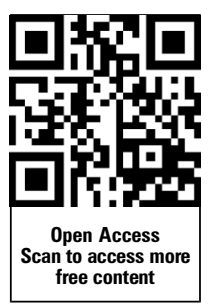

To cite: Thompson $\mathrm{LH}$ Salim M, Baloch CR, et al. Sex Transm Infect 2013:89: ii43-ii47.

\section{ABSTRACT}

Background We sought to describe the characteristics and operational dynamics of male sex workers (MSW) and hijra sex workers (HSWs) in 11 cities across Pakistan in 2011.

Methods We report descriptive statistics of self-reported sexual behaviour data from cross-sectional mapping and biological and behavioural surveys conducted among 1431 MSWs and 1415 HSWs in four cities across Pakistan in 2011.

Results While Karachi had the largest numbers of MSWs and HSWs, Quetta had the largest relative population sizes, with 3.6 MSWs per 1000 male adults and $3.3 \mathrm{HSWs}$ per 1000 male adults. There was considerable variability in the proportion of HSWs who operate through deras, ranging from $2.2 \%$ in Peshawar to $62.7 \%$ in Karachi. The number of HSWs per guru varies by city, from 1.5 in Quetta to $16.5 \mathrm{HSWs}$ per guru in Karachi. Among HSWs, the use of mobile phones for solicitation ranged from $37.6 \%$ in Quetta to $83 \%$ in Peshawar and among MSWs the use of mobile phones ranged from $27 \%$ in Karachi to $52 \%$ in Quetta. In Quetta, a large proportion of HSWs (41\%) find clients through gurus. Client volume tended to be higher among HSWs and among both MSWs and HSWs in Quetta and Peshawar. Condom use with clients was most consistent in Quetta, with 31\% of MSWs and 41\% of HSWs reporting always using condoms with clients. Peshawar had the greatest proportion reporting never using condoms.

Conclusions There is considerable geographic heterogeneity in the characteristics and operational dynamics of MSWs and HSWs across Pakistan.

\section{INTRODUCTION}

In Pakistan, HIV is concentrated among key populations at a higher risk of HIV; specifically, injection drug users and sex workers. In 2011, it was estimated that there were over 19000 male sex workers (MSWs) and 23000 hijra (transgender) sex workers (HSWs) in 14 major cities across Pakistan. ${ }^{1}$ MSWs receive money or goods in exchange for sex with other men, and in Pakistan have been found to identify themselves according to their sexual behaviours rather than by a sexual identity that is considered subversive in Pakistan, and conceal the fact that they have sex with other men. ${ }^{2}$ Generally, they do not operate through networks of other MSWs and rather operate independently to solicit clients, typically in public places. $^{2}{ }^{3}$ Hijras form a distinct sociocultural group unique to South Asia, considered to be a third gender. ${ }^{4}$ Most hijras are born as physiological males and dress in feminine attire, and some undergo castration. ${ }^{3}$ The traditional social role of hijras involved performances and blessings at weddings, births and shops. Today, many hijras beg and receive money or goods in exchange for sex with men, operating out of deras, which are houses operated by a guru. The HSW community is very hierarchal, headed by gurus (literally meaning a teacher or a spiritual leader) who adopt young HSWs as their chelas (students) and connect them with clients. The chela usually lives under the supervision and mentorship of the guru, living in the guru's dera, sharing her income with the guru, and eventually becomes a guru herself. Senior gurus oversee and are revered by junior gurus. HSWs typically operate through big networks encompassing other HSWs, gurus and deras.

In the socially conservative Islamic Republic of Pakistan, sex outside of the context of marriage or with members of the same sex is not tolerated and may result in considerable social and legal repercussions. ${ }^{4}$ Non-marital sex, commercial sex work and sodomy were originally prohibited by the Pakistan Penal Code of 1860 under colonial rule ${ }^{5}$ and later by the Hudood Ordinance, ${ }^{i}$ a compilation of Islamic laws enacted in 1979, which incorporate punishments of lashings and death by stoning. ${ }^{6}$ In this context, MSWs and HSWs are highly stigmatised and have been driven 'underground' out of fears of discrimination, violence, and harassment and arrest by the police. ${ }^{4} 78$ These fears drive MSWs and HSWs into potentially unsafe places, reducing their ability to negotiate condom use, and limiting their access to services and the ability of outreach workers to contact them.

The HIV prevalence has been the highest among injection drug users, with the national weighted prevalence estimated to be $38 \%$ in $2011 .^{1}$ In 2011 , the HIV prevalence was estimated to be $7.2 \%$ among HSWs and 3.1\% among MSWs, indicating a considerable recent increase. ${ }^{1}$ Although most sexual transmission of HIV in Pakistan has occurred through heterosexual contact without a condom, HIV transmission also occurs through unprotected

iThe Hudood Ordinance is a law in Pakistan that was enacted in 1979 to implement Islamic Shari'a law by enforcing punishments mentioned in the Quran and Sunnah for Zina (extramarital sex), Qazf (false accusation of zina), Offence Against Property (theft) and Prohibition (of alcohol consumption). 
sexual activity with members of the same sex in Pakistan, ${ }^{3}$ partly due to the fact that HIV transmission is more likely to occur during anal sex than other forms of sex. ${ }^{4} 910$ This, in combination with structural vulnerabilities that impede condom negotiation, safety and access to services, places MSWs and HSWs at risk for HIV infection. ${ }^{2-4} 1112$ Given the societal and legal intolerance towards homosexuality and sex work, few services addressing the unique needs of this population are available.

To characterise key populations at a higher risk of HIV and assess their behavioural risks and vulnerabilities, second generation HIV surveillance was conducted via serial cross-sectional integrated biological and behavioural surveys (IBBS). Using data collected during the 2011 round of IBBS, we sought to examine characteristics and behaviours pertaining to sex work, HIV risk, and structural vulnerabilities among MSWs and HSWs in four cities of Pakistan.

\section{METHODS}

\section{Study setting and data collection}

Cross-sectional mapping and IBBS were conducted among MSWs and HSWs in 11 cities in Pakistan from March to September 2011 as part of the Canada-Pakistan HIV/AIDS Surveillance Project.

Any male person who was 13 years of age or older and provided sexual services to another male person in return for money or other financial benefits was eligible to participate in the study and any hijra individual who was 15 years of age or older and provided sexual services to male persons in return for money or other financial benefits was also eligible. The target sample size was 360 MSWs and 356 HSWs in each city. In cities with smaller MSW and HSW populations, all who were eligible and interested in participating in the study were enrolled. In total, interviews were conducted among 1431 MSWs and 1415 HSWs in Lahore, Karachi, Peshawar and Quetta.

Geographic and network mapping were used to identify locations and networks through which MSWs and HSWs solicit clients and perform sex work. ${ }^{1} 13$

Through a rigorous effort which included focus group discussions, indepth interviews and snowball sampling with known HSW population members in each geographic zone, an exhaustive list of gurus was developed. By interviewing members of this initial list, additional gurus were systematically identified through snowball sampling within each zone. Gurus provided information used to estimate the number of HSWs in this network mapping approach. To obtain behavioural information, HSWs were recruited randomly at randomly selected deras and interviewed.

To estimate the size of the MSW population, geographic mapping was used. The field operations of the geographic approach comprised of two major phases, referred to as 'levels'. In Level 1, secondary key informants (eg, taxi/rickshaw drivers, shopkeepers, public call office operators) were interviewed about the locations ('hot spots') where MSWs solicit clients. In Level 2, primary key informants (MSWs) were interviewed at each hot spot to validate information collected in Level 1 and to collect more accurate information about the hot spot. In addition to population size estimates, information about how MSWs operate was also collected. To obtain specific behavioural information, MSWs were recruited randomly through multistage cluster sampling at the 10 hot spots with the highest estimated number of MSWs.

Interviews were conducted at a central field office. After informed consent was obtained, a structured questionnaire was administered by trained interviewers in the local language to obtain information on demographic characteristics, sex work and migration, sexual behaviour, access to intervention programming, and knowledge of sexually transmitted infections (STIs)/HIV. Blood was collected for dried blood spot from a finger prick using a lancet. HIV testing was carried out at the National HIV/STI reference laboratory, Islamabad and Armed Forces Institute of Pathology, Rawalpindi. All participants were referred for voluntary counselling and testing for HIV, and given information on HIV prevention and local services available for MSWs.

\section{Data analysis}

Data were double-entered using Microsoft Access and statistical analysis was performed using SPSS V.19.0. To describe observed differences in MSW and HSW populations in different geographic regions of Pakistan, we restricted our analysis to the four provincial capitals: Lahore, Karachi, Quetta and Peshawar. We reported descriptive statistics for characteristics of MSWs and HSWs in the four cities, including method of client solicitation, client volume in the past month, condom use with clients and knowledge of service delivery programmes (SDPs). The ethnic composition and migration dynamics of both groups were explored using self-identified mother tongue to assess their ethnic origin along with migration.

The institutional review boards of HOPE International in Pakistan and the Public Health Agency of Canada provided ethical approval for the study. Monetary compensation was provided to participants for their time in accordance with suggestions and discussions with local MSW and HSW communities during study planning.

\section{RESULTS}

Through mapping, it was estimated that there were 10463 MSWs and 11024 HSWs in the four selected cities, with the most MSWs (6 742) and HSWs (9069) in Karachi and the fewest in Peshawar (1108 and 456, respectively) (table 1). The estimated numbers of MSWs and HSWs per 1000 adult males were variable across the four cities, with the highest proportions in Quetta (3.6 MSWs per 1000 male adults and 3.3 HSWs per 1000 male adults). Lahore had the smallest relative number of MSWs (0.5 per 1000 male adults) and Peshawar had the smallest relative number of HSWs (0.6 per 1000 male adults).

To examine the extent of the HSW network, linkages among HSWs, gurus and deras were investigated. There was considerable variability in the proportion of HSWs who operate through deras, ranging from $2.2 \%$ in Peshawar to $62.7 \%$ in Karachi (table 2). On a peak day, the number of HSWs per dera ranged from 5.8 in Peshawar to 11.5 in Quetta. The number of HSWs per guru varies by city, from 1.5 in Quetta to 16.5 HSWs per guru in Karachi. In Lahore and Peshawar, there appeared to be a strong network of gurus, with each guru knowing 20.7 and 15.2 other gurus, respectively, compared with Quetta where on average each guru only knew about one other guru.

In all cities but Lahore a larger proportion of HSWs had migrated to their city of residence compared with MSWs (table 3). Karachi had the highest proportions of MSWs and HSWs who were migrants $(21 \%$ and $36 \%$, respectively) and Peshawar had the fewest (3.7\% and 20\%, respectively). Mother tongue was used as an indicator of the range of ethnicities present in each city, with the greatest diversity of both MSWs and HSWs in Quetta. Karachi shows a predominance of Urdu- and Punjabi-speakers in both sex worker groups, while in 
Table 1 Mapping data of MSW and HSW

\begin{tabular}{lclllll}
\hline City & $\begin{array}{l}\text { \# MSW } \\
\text { spots }\end{array}$ & $\begin{array}{l}\text { Estimated total \# MSW } \\
\text { (minimum, maximum) }\end{array}$ & $\begin{array}{l}\text { Estimated \# } \\
\text { MSW/spot }\end{array}$ & $\begin{array}{l}\text { MSW/1000 } \\
\text { males }\end{array}$ & $\begin{array}{l}\text { Estimated total \# HSW } \\
\text { (minimum, maximum) }\end{array}$ & $\begin{array}{l}\text { HSW/1000 } \\
\text { males }\end{array}$ \\
\hline Lahore & 293 & $1361(1170-1552)$ & 4.6 & 0.5 & $3643(3123-4163)$ & 1.8 \\
Karachi & 1023 & $6742(5723-7761)$ & 6.6 & 1.4 & $9,069(8384-9753)$ & 1.9 \\
Peshawar & 190 & $1108(954-1261)$ & 5.8 & 1.4 & $456(362-550)$ & 0.6 \\
Quetta & 260 & $1252(1039-1464)$ & 4.8 & 3.6 & $1147(1048-1245)$ & 3.3 \\
\hline
\end{tabular}

HSW, hijra sex workers; MSW, male sex workers.

Lahore $88 \%$ of both MSWs and HSWs speak Punjabi. In Peshawar, $80 \%$ of MSWs and 75\% of HSWs speak Pashto.

The methods of client solicitation varied across cities (table 3 ). In general, mobile phone use for solicitation was quite common. Among HSWs, the use of mobile phones for solicitation ranged from $37.6 \%$ in Quetta to $83 \%$ in Peshawar and among MSWs use of mobile phones ranged from $27 \%$ in Karachi to $52 \%$ in Quetta. Generally, roaming around to find clients was more common among MSWs and was the highest among both groups in Karachi (69.4\% of MSWs and 52.6\% of HSWs). In Quetta, a large proportion of HSWs (41\%) find clients through gurus.

Client volume tended to be higher among HSWs and was the highest among both MSWs and HSWs in Quetta and Peshawar, where the mean reported client volumes were over 50 per month compared with 22-31 per month in Karachi and Lahore (table 3). HSWs in Quetta had the most number of clients per month, with $45 \%$ reporting 90 or more. MSWs and HSWs in Lahore had the fewest clients, with $74 \%$ of MSWs and $67 \%$ of HSWs reporting fewer than 30 per month.

Condom use with clients was most consistent in Quetta, with $31 \%$ of MSWs and $41 \%$ of HSWs reporting always using condoms with clients. Only 9\% of MSWs in Karachi reported always using condoms, although the proportion reporting never using condoms was also quite low: $25 \%$ among MSWs and $17 \%$ among HSWs. Peshawar had the greatest proportion of MSWs (48\%) and HSWs (50\%) reporting never using condoms. In all four cities, HSWs were more aware of SDPs compared with MSWs. In general, MSWs and HSWs were more aware of SDPs in Karachi and less aware of them in Peshawar and Lahore. Among MSWs, awareness of SDPs ranged from $0 \%$ in Peshawar and $0.8 \%$ in Lahore to $20.9 \%$ in Karachi. Among HSWs, this knowledge ranged from 2.3\% in Peshawar to $53.5 \%$ in Karachi.

\section{DISCUSSION}

MSWs and HSWs form two distinct groups in Pakistan, both of which exhibit considerable geographic heterogeneity in characteristics and behaviours. ${ }^{3} 1314$ In this study, we found differences in client volume, methods of client solicitation, condom use and knowledge of SDPs across the four provincial capitals, all of which have important implications for HIV prevention.

Generally, MSWs and HSWs in the more conservative cities of Quetta and Peshawar had higher client volumes and were more likely to solicit clients through mobile phones and gurus, whereas in Karachi and Lahore solicitation was more common in public places and deras. In socially conservative contexts, there is a need for sex workers to be more 'hidden" 15 thereby increasing reliance on mobile phones and networks to find clients. Also, established locations of commercial sex work such as deras may be discouraged as they could be targeted by police or the Taliban.

Condom use was generally quite low across all cities, with the largest proportion of MSWs and HSWs reporting always using condoms in Quetta, which had recently implemented its first SDP, and the smallest proportion reporting never using them in Karachi, which had the longest running SDP of the four cities. Several studies have demonstrated that female sex workers exposed to HIV prevention programmes in Karnataka, India, report increased condom use, particularly with their clients. ${ }^{16-19}$ Among the four cities included in our study, Peshawar was the only city to not have an existing SDP, which may partially explain the low condom use. A previous study found that among the few who used condoms in Peshawar, the majority had purchased the condoms themselves. ${ }^{3}$ The relatively high rate of condom use reported in Quetta may be related both to the presence of a SDP and the reliance on gurus, who may encourage condom use and/ or the reporting of condom use, whether or not it actually takes place.

The fact that most MSWs and HSWs do not always use condoms with clients is concerning, especially considering the recent increase in HIV prevalence among HSWs and MSWs. ${ }^{20}$ This demonstrates the need for effective HIV prevention strategies reaching a large proportion of the MSW and HSW populations across Pakistan. It is important to consider local patterns of client volume, solicitation, and condom use when planning and implementing SDPs for HIV prevention and to understand the influence that social context may have both on the dynamics of sex work and the optimal configuration and delivery of HIV

Table 2 Network mapping assessment of dera-based HSWs in four cities in Pakistan

\begin{tabular}{|c|c|c|c|c|c|c|}
\hline \multirow[b]{2}{*}{ City } & \multirow[b]{2}{*}{$\%$ Dera-based } & \multirow[b]{2}{*}{ \# HSWs per guru } & \multirow[b]{2}{*}{ \# Gurus each guru knows } & \multirow[b]{2}{*}{ \# HSWs each guru knows } & \multicolumn{2}{|c|}{$\begin{array}{l}\text { \# HSW per dera in } \\
\text { a day }\end{array}$} \\
\hline & & & & & Usual & Peak \\
\hline Lahore & 26.3 & 5.5 & 20.7 & 70.4 & 4.3 & 7.7 \\
\hline Karachi & 62.7 & 16.5 & 8 & 63 & 3.6 & 6 \\
\hline Peshawar & 2.2 & 3.4 & 15.2 & 84.8 & 3.3 & 5.8 \\
\hline Quetta & 8.8 & 1.5 & 0.9 & 18.5 & 6.4 & 11.5 \\
\hline
\end{tabular}


Table 3 Characteristics of MSWs and HSWs

\begin{tabular}{|c|c|c|c|c|c|c|c|c|}
\hline \multirow[b]{2}{*}{ Characteristics } & \multicolumn{2}{|l|}{ Quetta } & \multicolumn{2}{|l|}{ Karachi } & \multicolumn{2}{|l|}{ Lahore } & \multicolumn{2}{|l|}{ Peshawar } \\
\hline & $\begin{array}{l}\text { MSW (n=359) \% } \\
(95 \% \text { Cl) }\end{array}$ & $\begin{array}{l}\text { HSW }(n=338) \% \\
(95 \% \mathrm{Cl})\end{array}$ & $\begin{array}{l}\text { MSW }(n=360) \% \\
(95 \% \text { Cl) }\end{array}$ & $\begin{array}{l}\text { HSW }(n=359) \% \\
(95 \% \text { Cl) }\end{array}$ & $\begin{array}{l}\text { MSW }(n=360) \% \\
(95 \% \text { Cl) }\end{array}$ & $\begin{array}{l}\text { HSW }(n=366) \% \\
(95 \% \text { Cl) }\end{array}$ & $\begin{array}{l}\text { MSW (n=352) \% } \\
(95 \% \text { Cl) }\end{array}$ & $\begin{array}{l}\text { HSW }(n=352) \% \\
(95 \% \text { Cl) }\end{array}$ \\
\hline In-migrant & 20.6 (16.4 to 24.8 ) & 29.6 (24.7 to 34.5 ) & 21.1 (16.9 to 25.3$)$ & 35.7 (30.7 to 40.7 ) & 18.6 (14.6 to 22.6$)$ & 16.9 (13.1 to 20.7$)$ & 3.7 (1.7 to 5.7$)$ & 20.2 (16.0 to 24.4$)$ \\
\hline \multicolumn{9}{|c|}{ Language (mother tongue) } \\
\hline Urdu & $13.4(9.9$ to 16.9$)$ & 13.3 (9.7 to 16.9$)$ & 35.6 (30.7 to 40.6$)$ & 40.4 (35.3 to 45.5$)$ & $10.0(6.9$ to 13.1$)$ & 9.0 (6.1 to 11.9 ) & 13.6 (10.0 to 17.2$)$ & 8.2 (5.3 to 11.1 ) \\
\hline Punjabi & 21.2 (17.0 to 25.4$)$ & 19.8 (15.6 to 24.1$)$ & 27.8 (23.2 to 32.4$)$ & 36.2 (31.2 to 41.2 ) & 88.3 (85.0 to 91.6 ) & 88.8 (85.6 to 92.0 ) & 3.7 (1.7 to 5.7$)$ & 1.4 (0.2 to 2.6$)$ \\
\hline Sindhi & 20.7 (16.5 to 24.9$)$ & $14.2(10.5$ to 17.9$)$ & $9.2(6.2$ to 12.2$)$ & $12.0(8.6$ to 15.4$)$ & 0.0 & 0.0 & $0.3(0.3$ to 0.9$)$ & 0.9 (0.1 to 1.9$)$ \\
\hline Pashto & 22.6 (18.3 to 26.9$)$ & 21.0 (16.7 to 25.3$)$ & 9.2 (6.2 to 12.2$)$ & 5.3 (3.0 to 7.6$)$ & 0.6 (0.2 to 1.4$)$ & $1.4(0.2$ to 2.6$)$ & 79.5 (75.3 to 83.7$)$ & 75.3 (70.8 to 79.8 ) \\
\hline Baluchi & 5.0 (2.8 to 7.3$)$ & $13.3(9.7$ to 16.9$)$ & $1.9(0.5$ to 3.3$)$ & 0.0 & 0.0 & 0.0 & $0.3(0.3$ to 0.9$)$ & 0.0 \\
\hline Other & 17.1 (13.2 to 21.0$)$ & 18.4 (14.3 to 22.5$)$ & 16.4 (12.6 to 20.2$)$ & 6.2 (3.7 to 8.7$)$ & 1.1 (0.0 to 2.2$)$ & 0.8 (0.1 to 1.7$)$ & 2.6 (0.9 to 4.3$)$ & 14.2 (10.6 to 17.9$)$ \\
\hline \multicolumn{9}{|l|}{ Client solicitation } \\
\hline Guru & 0.3 (0.3 to 0.9$)$ & 40.9 (35.7 to 46.1$)$ & 0.0 & $0.6(0.2$ to 1.4$)$ & 0.0 & 12.9 (9.5 to 16.3$)$ & $4.0(2.0$ to 6.1$)$ & $3.2(1.4$ to 5.0$)$ \\
\hline Mobile phone & 52.0 (46.8 to 57.2 ) & 37.6 (32.4 to 42.8$)$ & 27.0 (22.4 to 31.6 ) & 40.9 (35.8 to 46.0$)$ & 36.7 (31.7 to 41.7 ) & 53.2 (48.1 to 58.3 ) & $54.8(49.6$ to 60.0$)$ & 83.0 (79.1 to 86.9$)$ \\
\hline Roaming & 43.6 (38.5 to 48.7$)$ & 14.3 (10.6 to 18.0$)$ & 69.4 (64.6 to 74.2 ) & 52.6 (47.4 to 57.8$)$ & 53.9 (48.8 to 59.1$)$ & 25.8 (21.3 to 30.3 ) & 23.9 (19.4 to 28.4$)$ & $9.2(6.2$ to 12.2$)$ \\
\hline Existing/old clients & 4.2 (2.1 to 6.3$)$ & $7.2(4.4$ to 10.0$)$ & 3.1 (1.3 to 4.9$)$ & 5.6 (3.2 to 8.0$)$ & 9.2 (6.2 to 12.2$)$ & $8.2(5.4$ to 11.0$)$ & 17.3 (13.4 to 21.3$)$ & 4.6 (2.4 to 6.8$)$ \\
\hline Other & 0.0 & 0.0 & 0.6 (0.2 to 1.4$)$ & $0.3(0.3$ to 0.9$)$ & $0.3(0.3$ to 0.9$)$ & 0.0 & 0.0 & 0.0 \\
\hline \multicolumn{9}{|l|}{ Clients per month } \\
\hline$<30$ & 9.8 (6.7 to 12.9$)$ & 10.4 (7.2 to 13.7 ) & $42.8(37.7$ to 47.9$)$ & 49.0 (43.8 to 54.2 ) & 74.2 (69.7 to 78.7$)$ & $66.9(62.1$ to 71.7$)$ & 6.5 (3.9 to 9.1 ) & 16.2 (13.4 to 20.1$)$ \\
\hline $30-59$ & 51.4 (46.2 to 56.6$)$ & 19.9 (15.6 to 24.2$)$ & $50.8(45.6$ to 56.0$)$ & 40.9 (35.8 to 46.0$)$ & 21.1 (16.9 to 25.3 ) & 20.8 (16.6 to 25.0$)$ & 38.1 (33.0 to 43.2 ) & 12.5 (9.1 to 16.0$)$ \\
\hline $60-89$ & 32.7 (27.9 to 37.6$)$ & 24.9 (20.1 to 29.5$)$ & $4.2(2.1$ to 6.3$)$ & 5.0 (2.8 to 7.3$)$ & $1.9(0.5$ to 3.3$)$ & 3.6 (1.7 to 5.5$)$ & 45.5 (40.3 to 50.7$)$ & 47.2 (42.0 to 52.4$)$ \\
\hline $90+$ & 6.1 (3.6 to 8.6 ) & 44.8 (39.5 to 50.1 ) & 2.2 (0.7 to 3.7$)$ & 5.0 (2.8 to 7.3$)$ & 2.8 (1.1 to 4.5$)$ & 8.7 (5.8 to 11.6$)$ & 9.9 (6.8 to 13.0$)$ & 24.1 (19.6 to 28.6 ) \\
\hline $\begin{array}{l}\text { Mean \# clients last } \\
\text { month (SD) }\end{array}$ & $54(20)$ & $84(57)$ & $31(19)$ & $29(15)$ & $22(12)$ & $22(16)$ & $56(18)$ & $66(26)$ \\
\hline \multicolumn{9}{|c|}{ Condom use with clients } \\
\hline Always & 31.4 (26.6 to 36.2 ) & 40.5 (35.3 to 45.7$)$ & $9.2(6.2$ to 12.2$)$ & 24.1 (19.7 to 28.5$)$ & 17.5 (13.6 to 21.4$)$ & 24.2 (19.8 to 28.6 ) & 18.5 (14.4 to 22.6$)$ & 24.3 (19.9 to 28.8 ) \\
\hline Never & 36.4 (31.4 to 41.4$)$ & 25.2 (20.6 to 29.8 ) & 24.9 (20.4 to 29.4$)$ & 17.3 (13.4 to 21.2 ) & 32.5 (27.7 to 37.3$)$ & 40.7 (35.7 to 45.7 ) & 48.0 (42.8 to 53.2 ) & 50.1 (44.9 to 55.3 ) \\
\hline Knowledge of SDP & 8.1 (5.3 to 10.9 ) & 30.1 (25.2 to 35.0$)$ & 20.9 (16.7 to 25.1$)$ & 53.5 (48.3 to 58.7$)$ & $0.8(0.1$ to 1.7$)$ & $15.7(12.0$ to 19.4$)$ & 0.0 & 2.3 (0.7 to 3.9 ) \\
\hline
\end{tabular}

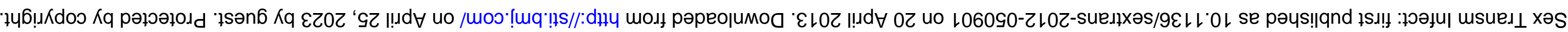


prevention programmes. In socially conservative settings, HIV prevention programmes may experience considerable barriers to providing services to marginalised populations, including difficulties in connecting with more 'hidden' sex workers operating through networks to avoid harassment and violence and also public resistance to the presence of targeted HIV prevention programmes. ${ }^{4} 2122$ From a policy perspective, it is important to acknowledge that a one size fits all approach will not work for HIV prevention programmes across Pakistan. In some contexts, it may be important to access MSWs and HSWs through networks of sex workers and gurus, whereas in other contexts, placing programme sites near common public solicitation sites may be more effective.

Our findings are limited to Pakistan's four capital cities in 2011. We performed an unweighted descriptive analysis to highlight the geographic heterogeneity of the characteristics and behaviours of MSWs and HSWs by comparing four cities not intended to be representative of the whole country. Although these provincial capitals may reflect sociocultural differences present across Pakistan's four provinces, differences exist within provinces as well and may be related to rural environments, proximity to national borders or zones of military and ethnic conflict, economic differences, and local industries. We emphasise the importance of tailoring HIV prevention programmes to the unique needs and constraints of the local context. Also, our findings are limited to the level of detail collected through the surveillance programme and the cross-sectional nature of the study. The influence of social conservatism on the dynamics of sex work in Pakistan and the importance of gurus in influencing condom use require further study.

\section{Key messages}

- Male and hijra (transgender) sex workers are at a high risk of HIV infection in Pakistan.

- There is considerable geographic heterogeneity in the characteristics and operational dynamics of male and hijra sex workers across Pakistan.

- Knowledge of the local characteristics and operational dynamics of these populations is essential to design appropriate and effective HIV prevention programmes.

- In some cities, these populations may be best accessed through networks while in others public solicitation sites may be more effective.

Acknowledgements We thank the surveillance team for their efforts in mapping, data collection, specimen collection and data entry. We thank the community members who took part in the surveys for their time and participation.

Contributors LHT and MS performed data analysis and co-wrote the manuscript. CRB was involved in the design of the study and critically reviewed the manuscript. TR contributed to data analysis and critically reviewed the manuscript. NM, ND and SA were involved in the design of the study and critically reviewed the manuscript. JFB was involved in the design of the study, critically reviewed the manuscript and led the development of the special supplement strategy. FE contributed to study design and critically reviewed the manuscript.

Funding The Canada-Pakistan HIVIAIDS Surveillance Projected was funded by the Canadian International Development Agency (contract number CIDA PK 30849).

Competing interests None.
Ethics approval The institutional review boards of HOPE International in Pakistan and the Public Health Agency of Canada provided ethical approval for the study.

Provenance and peer review Commissioned; externally peer reviewed.

Open Access This is an Open Access article distributed in accordance with the Creative Commons Attribution Non Commercial (CC BY-NC 3.0) license, which permits others to distribute, remix, adapt, build upon this work non-commercially, and license their derivative works on different terms, provided the original work is properly cited and the use is non-commercial. See: http://creativecommons.org/ licenses/by-nc/3.0/

\section{REFERENCES}

1 Pakistan National AIDS Control Program and Canada-Pakistan HIVIAIDS Surveillance Project. Pakistan high-risk groups mapping report. Islamabad, 2011. http://www. nacp.gov.pk/surveillance and research/ (accessed 10 Mar 2013).

2 Collumbien M, Qureshi A, Mayhew SH, et al. Understanding the context of male and transgender sex work using peer ethnography. Sex Transm Infect 2009:85 (Suppl 2):ii3-7.

3 Shaw SY, Emmanuel F, Adrien A, et al. The descriptive epidemiology of male sex workers in Pakistan: a biological and behavioural examination. Sex Transm Infect 2011;87:73-80

4 Rajabali A, Khan S, Warraich HJ, et al. HIV and homosexuality in Pakistan. Lancet Infect Dis 2008:8:511-15.

5 Government of Pakistan. Pakistan Penal Code, October 6th, 1860. http://www. pakistani.org/pakistan/legislation/1860/actXLVof1860.html (accessed 8 Jan 2012).

6 Government of Pakistan. Hudood Laws. http://www.pakistani.org/pakistan/ legislation/hudood.html (accessed 8 Jan 2012).

7 Mayhew S, Collumbien M, Qureshi A, et al. Protecting the unprotected: mixed-method research on drug use, sex work and rights in Pakistan's fight against HIVIAIDS. Sex Transm Infect 2009:85(Suppl 2):ii31-6.

8 Hawkes S, Collumbien M, Platt L, et al. HIV and other sexually transmitted infections among men, transgender and women selling sex in two cities in Pakistan: a cross-sectional prevalence survey. Sex Transm Infect 2009;85(Suppl 2):ii8-16.

9 Khan AA, Rehan N, Qayyum K, et al. Correlates and prevalence of HIV and sexually transmitted infections among Hijras (male transgenders) in Pakistan. Int J STD AIDS 2008; 19:817-20

10 Van Griensven F, de Lind van Wijngaarden JW. A review of the epidemiology of HIV infection and prevention responses among MSM in Asia. AIDS 2010;24(Suppl 3): S30-40.

11 Chan PA, Khan OA. Risk factors for HIV infection in males who have sex with males (MSM) in Bangladesh. BMC Public Health 2007;7:153

12 Pappas G, Khan 0, Wright JT, et al. Males who have sex with males (MSM) and HIVIAIDS in India: the hidden epidemic. AIDS Public Policy J 2001:16;4-17.

13 Emmanuel F, Blanchard J, Zaheer HA, et al. The HIVIAIDS surveillance project mapping approach: An innovative approach for mapping and size estimation for groups at a higher risk of HIV in Pakistan. AIDS 2010:24(Suppl 2):S77-84.

14 Bokhari A, Nizamani NM, Jakcson DJ, et al. HIV risk in Karachi and Lahore, Pakistan: an emerging epidemic in injecting and commercial sex networks. Int J STD AIDS 2007; 18:486-92.

15 Mumtaz G, Hilmi N, McFarland W, et al. Are HIV epidemics among men who have sex with men emerging in the Middle East and North Africa?: a systematic review and data synthesis. PLOS Med 2010;8:e1000444.

16 Lowndes CM, Alary M, Verma S, et al. Assessment of intervention outcome in the absence of baseline data: 'reconstruction' of condom use time trends using retrospective analysis of survey data. Sex Transm Infect 2010;86(Suppl 1):i49-55.

17 Lipovsek V, Mukherjee A, Navin D, et al. Increases in self-reported consistent condom use among male clients of female sex workers following exposure to an integrated behaviour change programme in four states in southern India. Sex Transm Infect 2010:86(Suppl 1):i25-32.

18 Deering KN, Boily MC, Lowndes CM, et al. A dose-response relationship between exposure to a large-scale HIV preventive intervention and consistent condom use with different sexual partners of female sex workers in southern India. BMC Public Health 2011;11(Suppl 6):S8.

19 Gurung A, Narayanan P, Prabhakar P, et al. Large-scale STI services in Avahan improve utilization and treatment seeking behaviour amongst high-risk groups in India: an analysis of clinical records from six states. BMC Public Health 2011;11 (Suppl 6):S10

20 Pakistan National AIDS Control Program. HIV Second Generation Surveillance in Pakistan-Round 4. Islamabad. 2012. http://www.nacp.gov.pk/library/reports/ (accessed 10 Mar 2013).

21 Todd CS, Nassiramanesh B, Stanekzai MR, et al. Emerging HIV epidemics in Muslim countries: assessment of different cultural responses to harm reduction and implications for HIV control. Curr HIVIAIDS Rep 2007:4:151-7.

22 Obermeyer CM. HIV in the Middle East. BMJ 2006;333:851-4. 